\title{
Efeitos dos rejeitos da indústria de zinco na anatomia e crescimento de plantas jovens de Salix humboldtiana Willd. (salgueiro)
}

\author{
Marcelo Pedrosa Gomes ${ }^{1}$, Teresa Cristina Lara Lanza de Sá e Melo Marques², Mariana de Oliveira \\ Gonçalves Nogueira ${ }^{3}$, Guilherme Henrique Silva ${ }^{4}$, Evaristo Mauro de Castro ${ }^{3}$ e Ângela Maria Soares ${ }^{3,5}$
}

Recebido: 9.04.2010; aceito: 17.03.2011

\begin{abstract}
Effects of tailings from zinc industry in the anatomy and growth of young plants of Salix humboldtiana Willd. (willow)). The heavy metal pollution caused mainly by mining and industrial activities requires studies for the recovery of contaminated areas. Thus, we studied growth and anatomical characteristics responses of young willow plants grown in heavy metal multicontaminated soil. Plants were grown in three mixture levels of contaminated soil: $0 \%, 15 \%$ and $30 \%(\mathrm{v} / \mathrm{v})$ for 60 days. At the highest level of contamination was noted a less dry matter production of roots and shoots and reduced root growth. Accordingly, the roots exhibited epidermis, exodermis and endodermis thicker, and a smaller number of conducting elements of xylem. Leaves showed changes in the number of conducting elements of xylem diameter and density of stomata, and epidermis, endodermis, collenchyma and mesophyll cell thickness.
\end{abstract}

Key words: anatomic plasticity, growing, tolerance, willow

RESUMO - (Efeitos dos rejeitos da indústria de zinco na anatomia e crescimento de plantas jovens de Salix humboldtiana Willd. (salgueiro)). A poluição por metais pesados, gerada principalmente pelas atividades de mineração e industrial, exige estudos que possibilitem a recuperação de áreas contaminadas. Foram estudadas respostas de crescimento e características anatômicas de plantas jovens de salgueiro cultivadas em solo multicontaminado por metais pesados. As plantas foram cultivadas em três níveis de misturas de solo contaminado: 0\%; 15\% e 30\% (v/v), durante 60 dias. No maior nível de contaminação foi observado menor produção de matéria seca das raízes e da parte aérea e menor crescimento das raízes. Nesta condição, as raízes apresentaram maior espessura da epiderme, exoderme e endoderme e menor número de elementos condutores de xilema. As folhas apresentaram modificações no número de elementos condutores de xilema, na densidade e diâmetro dos estômatos, e na espessura da epiderme, endoderme, colênquima e do mesofilo.

Palavras-chave: crescimento, plasticidade anatômica, salgueiro, tolerância

\section{Introdução}

A poluição por metais pesados representa, hoje, uma importante forma de estresse para a comunidade vegetal devido à progressiva adição destes metais ao ambiente pelas atividades humanas. Esses metais, como o $\mathrm{Zn}, \mathrm{Cd}, \mathrm{As}, \mathrm{Ag}, \mathrm{Mn}$, são particularmente difíceis de serem retirados do solo, água ou ar, pois, diferentemente dos poluentes orgânicos que podem ser degradados a compostos não-tóxicos, são imutáveis pelas reações bioquímicas (Meagher \& Heaton 2005).
As plantas apresentam várias propriedades naturais que podem ser utilizadas como perspectivas para a absorção de poluentes do ambiente. Vários estudos têm demonstrado o potencial das plantas para a remediação de áreas degradas por metais pesados (Marques et al. 2000, Lux et al. 2004, Vollenweider et al. 2006), cuja técnica é conhecida como fitorremediação.

No vegetal, os metais pesados desencadeiam respostas fisiológicas e alterações em níveis estruturais e ultraestruturais, como a danificação de lipídeos de membrana, proteínas, pigmentos e ácidos nucléicos,

1. Universidade Federal de Minas Gerais, Instituto de Ciências Biológicas, Departamento de Botânica, Campus Pampulha, Caixa Postal 486, 31279-901 Belo Horizonte, MG, Brasil

2. Universidade Federal de Lavras, Departamento de Ciência do Solo, Caixa Postal 3037, 37200-000 Lavras, MG, Brasil

3. Universidade Federal de Lavras, Departamento de Biologia, Caixa Postal 3037, 37200-000 Lavras, MG, Brasil

4. Universidade Federal de Viçosa, Departamento de Zootecnia, 36570-000 Viçosa, MG, Brasil

5. Autor para correspondência: amsoares@dbi.ufla.br 
expressos em sintomas visuais como a redução no crescimento, produtividade e alterações morfológicas (Marques et al. 2000, Lux et al. 2004, Wójcik et al. 2005).

As plantas ao serem expostas aos metais pesados, além das alterações fisiológicas, apresentam também modificações morfológicas e anatômicas. Srighar et al. (2005) observaram a redução no tamanho das células do parênquima paliçádico e da epiderme foliar de Brassica juncea cultivadas em solo contaminado com Zn e Cd. A formação de espaços intercelulares no córtex radicular de Thlaspi caerulescens devido à degeneração de células, bem como pela morte celular induzida por Cd foi verificado por Wójcik et al. (2005).

No caso de estresse por metais pesados no solo, o sistema radicular é particularmente afetado por ser a parte da planta em contato direto com o contaminante (Degenhardt \& Gimmler 2000). Alguns estudos têm mostrado alterações na arquitetura e estrutura de raiz induzida por uma variedade de condições estressantes, tais como salinidade e metais pesados (Reinhardt \& Roswt 1995, Lux et al. 2004), e também alterações nas barreiras apoplásticas (Perumalla \& Peterson 1986, North \& Nobel 1995). Modificações na estrutura radicular em resposta a metais pesados podem estar diretamente relacionadas às alterações morfo-fisiológicas de todo o corpo vegetal, já que as raízes constituem a via primária de absorção de água e nutrientes. Sirdhar et al. (2005), em estudos com $\mathrm{Cd}$, verificaram que o metal ficou retido na raiz, sendo pouca quantidade translocada para a parte aérea.

Diversas espécies arbóreas vêm sendo estudadas em relação ao seu potencial de fitorremediação de áreas contaminadas. Devido ao rápido crescimento e à capacidade de acumular altos níveis de metais pesados em seus tecidos, o gênero Salix tem se mostrado adequado para a fitorremediação de áreas contaminadas por metais, como por exemplo, o Cd (Greger \& Landberg 1999, Lux et al. 2004). Modificações fisio-anatômicas têm sido descritas em plantas de Salix cultivadas na presença de metais pesados (Ederli et al. 2004, Vollenweider et al. 2006) provavelmente, desenvolvidas como estratégia que as permitem suportar níveis fitotóxicos destes metais em seus tecidos. Segundo Sirdhar et al. (2005), informações de fisiologia, morfologia e características anatômicas das plantas em resposta aos metais são de suma importância para a compreensão do processo de fitorremediação como um todo.
Nesse contexto, o presente trabalho objetivou avaliar o efeito da contaminação do solo por metais pesados: (i) na produção de biomassa e no crescimento e (ii) nas modificações anatômicas de raízes e folhas de plantas jovens de Salix humboldtiana.

\section{Material e métodos}

Para esse estudo foram utilizadas plantas jovens de Salix humboldtiana Willd., pertecente à família Salicaceae, de porte arbóreo, popularmente conhecida como chorão ou salgueiro. A espécie é típica de formações secundárias, ocorrendo principalmente em matas ciliares e regiões de solo úmido de beiras de rio (Lorenzi 1992).

O experimento foi conduzido em casa de vegetação do Departamento de Biologia da Universidade Federal de Lavras (UFLA), no município de Lavras, Minas Gerais. Utilizou-se solo contaminado com metais pesados coletado em área de rejeito da Companhia Mineira de Metais (CMM) situada em Três Marias, MG. A análise química deste solo revelou os seguintes resultados: (em mg kg${ }^{-1}$ de solo) 18600 de $\mathrm{Zn} ; 140$ de $\mathrm{Cd} ; 450$ de $\mathrm{Cu}$ e 410 de $\mathrm{Pb}$, extraído por água régia $\left(1 \mathrm{HNO}_{3}: 3 \mathrm{HCl}\right)$ (Forster 1995). Os tratamentos constaram de misturas de solo contaminado nas proporções de $0 \%, 15 \%$ e $30 \%$ (v/v) em Latossolo Amarelo coletado no campus da UFLA, cujas características físicoquímicas são apresentadas na tabela 1. Foram aplicados $400 \mathrm{mg} \mathrm{kg}^{-1}$ de P (superfosfato simples) à mistura de forma homogênea. Mudas de Salix humboldtiana oriundas de estacas, de um ano de idade e altura homogênea, adquiridas no Instituto Estadual de Florestas de Lavras, foram cultivadas em vaso contendo $6 \mathrm{~L}$ deste substrato, com uma planta por vaso correspondendo à uma unidade experimental, num total de 12 vasos por tratamento.

Ao final de 60 dias, para avaliar as características de crescimento, cinco plantas de cada tratamento foram coletadas e mediu-se, com auxilio de régua, os comprimentos do ramo principal e raiz principal. Posteriormente, foram separadas raízes e parte aérea, e após serem lavadas com água destilada, foram colocadas em sacos de papel e levadas para estufa com circulação constante de ar a $70{ }^{\circ} \mathrm{C}$ até massa constante, para posterior determinação da matéria seca.

Para as análises anatômicas, foram coletadas raízes laterais de aproximadamente $9 \mathrm{~cm} \mathrm{de}$ comprimento e folhas completamente expandidas, correspondente ao $3^{\circ}$ nó foliar a contar do ápice 
Tabela 1. Características químicas e físicas do Latossolo Amarelo coletado em área próxima ao campus da UFLA. pH em água, KCl e $\mathrm{CaCl}_{2}$ - Relação 1:2,5; P-Na-K-Fe-Zn-Mn-Cu - extrator Mehlich 1; Ca-Mg-Al- Extrator: KCl 1N; H+Al- Extrator: SMP; $\mathrm{S}$ - Extrator - Fosfato monocálcico em ácido acético.

Table 1. Chemical and physical characteristics of a Yellow Latosol collected nearby the UFLA campus. pH in water, $\mathrm{KCl}_{\mathrm{e} \mathrm{CaCl}}-\mathrm{Relation}_{2}$ 1:2,5; P-Na-K-Fe-Zn-Mn-Cu - extractor Mehlich 1; Ca-Mg-Al- Extractor: KCl 1N; H+Al- Extractor: SMP; S - Extractor - Monocalcium phosphate in acetic acid.

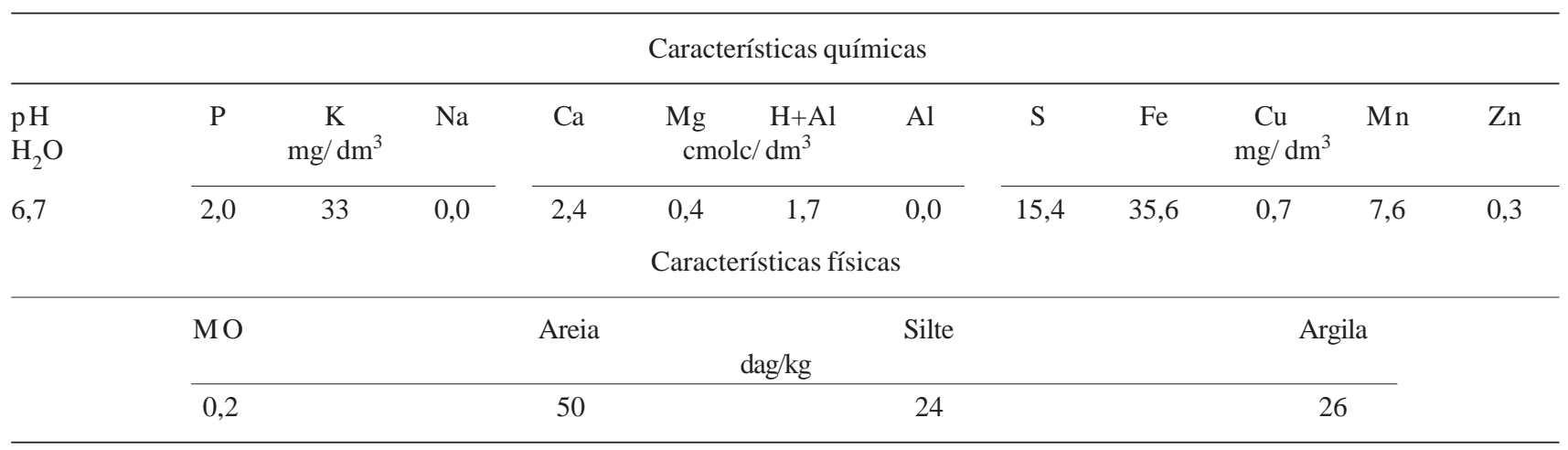

caulinar, de cinco indivíduos por tratamento, correspondentes às repetições. $\mathrm{O}$ material foi fixado em FAA 70 (formaldeído + ácido acético + álcool etílico 70\%) (Johansen 1940) por 72 horas e posteriormente conservado em álcool $70 \%$.

Foram obtidas secções transversais de $15 \mathrm{~mm}$ de espessura em micrótomo de mesa (modelo LPC, Rolemberg e Bhering Comércio e Importação Ltda., Belo Horizonte, Brasil) do terço médio foliar e a $4 \pm$ $0,5 \mathrm{~cm}$ do ápice das raízes. Os cortes paradérmicos foram realizados manualmente no terço médio das folhas. Para clarificação das secções transversais utilizou-se água sanitária 5\% (Kraus \& Arduin 1997) e uma mistura $2: 1$ de azul de astra $0,5 \%$ e safranina $0,5 \%$ para coloração. As secções paradérmicas foram coradas com solução de safranina $1 \%$. As lâminas foram montadas em glicerina $50 \%$ e foram fotomicrografadas em microscópio de luz (modelo TT18, Ken a Vision, New York, Estados Unidos da América) acoplado a uma câmera fotográfica (modelo A620, Canon Power Shot, Tóquio, Japão).

As avaliações de espessura de tecidos foliares e radiculares e de densidade estomática foram realizadas com auxilio de software Sigma Scan, em cinco locais distintos de cinco indivíduos, num total de 25 amostras avaliadas por tratamento. Para o sistema radicular foram avaliadas espessura da epiderme, exoderme e endoderme e o número total de elementos condutores de xilema. Para as folhas, as medições de altura e largura do feixe, espessura da endoderme (bainha do feixe), colênquima adaxial e abaxial e periciclo foram realizadas utilizando a nervura central do mesofilo foliar como padrão. As medições da epiderme da face adaxial, epiderme da face abaxial e da espessura do mesofilo foram realizadas na região intercostal. A densidade estomática foi expressa em número de estômatos por $\mathrm{mm}^{2}$, e foi medido o diâmetro polar e equatorial dos estômatos $(n=25)$.

$\mathrm{O}$ delineamento experimental utilizado foi $\mathrm{o}$ inteiramente casualizado. Os dados obtidos foram submetidos à análise de variância, as médias comparadas pelo teste de Tukey, a 5\% de probabilidade, utilizando-se o programa estatístico Sisvar 4.3 (Ferreira 1999).

\section{Resultados e Discussão}

Após 60 dias, constatou-se redução no crescimento radicular (CR) quando a planta foi exposta à contaminação por metais pesados (tabela 2). A produção de matéria seca das raízes (MSR) foi menor nos tratamentos com contaminação do solo (tabela 2). Sintomas visuais como o escurecimento e a formação de lesões necróticas nas raízes foram observados nos tratamentos contaminados. Diminuição do crescimento e da produção de matéria seca em resposta a metais pesados são amplamente relatadas na literatura (Kabata-Pendias \& Pendias 1992, Sanità-di-Toppi \& Gabbrielli 1999, Marques et al. 2000). Muitas destas respostas são associadas a danos na fotossíntese relacionados à capacidade que os metais pesados possuem em interferir na biossíntese de clorofilas, na atividade de enzimas do ciclo de Calvin e no PSII (Di Cagno et al. 1999) e também na produção de espécies reativas de oxigênio (EROs) (Benavides et al. 2005). 
Tabela 2. Efeito dos metais pesados nos valores médios do comprimento da raiz principal $\mathrm{CR}(\mathrm{cm})$, comprimento do ramo principal CC $(\mathrm{cm})$, massa seca de raiz MSR $(\mathrm{g})$, massa seca da parte aérea MSPA (g) e na razão MSR/MSPA de plantas jovens de Salix humboldtiana submetidas a diferentes níveis de contaminação do solo por metais pesados. Médias seguidas pela mesma letra na linha, não diferem estatisticamente entre si, pelo teste Tukey a $\mathrm{p} \leq 0,05(\mathrm{n}=5)$. * não significativo.

Table 2. Effect of heavy metals in the average values of the length of main root $\mathrm{CR}(\mathrm{cm})$, length of main branch $\mathrm{CC}(\mathrm{cm})$, dry mass of root MSR (g), dry mass of shoot MSPA (g) and in MSR/MSPA ratio of young plants of Salix humboldtiana submitted to different levels of soil contamination from heavy metal. Means followed by the same letter in the row do not differ statistically by the Tukey test at $\mathrm{p} \leq 0.05(\mathrm{n}=5)$. ${ }^{*}$ no significative.

\begin{tabular}{|c|c|c|c|}
\hline \multirow{2}{*}{$\begin{array}{l}\text { Características } \\
\text { avaliadas }\end{array}$} & \multicolumn{3}{|c|}{ Tratamentos } \\
\hline & $\begin{array}{c}\text { Controle } \\
0 \%\end{array}$ & $\begin{array}{c}\text { Contaminado } \\
15 \%\end{array}$ & $\begin{array}{c}\text { Contaminado } \\
30 \%\end{array}$ \\
\hline $\mathrm{CR}(\mathrm{cm})$ & $50,2 \mathrm{a}$ & $22,8 b$ & $18,2 b$ \\
\hline $\mathrm{CC}(\mathrm{cm})$ & $89,7 *$ & $67,5^{*}$ & $45,3^{*}$ \\
\hline MSR (g) & $2,0 \mathrm{a}$ & $0,9 b$ & $0,6 b$ \\
\hline MSPA (g) & $22,3 \mathrm{a}$ & $10,9 b$ & $9,5 \mathrm{c}$ \\
\hline MSR/MSPA & $0,08 \mathrm{a}$ & $0,07 \mathrm{ab}$ & $0,05 b$ \\
\hline
\end{tabular}

Embora se tenha observado danos acentuados no sistema radicular das plantas sobre contaminação, o comprimento do ramo principal (CC) não diferiu estatisticamente entre os tratamentos, enquanto a produção de matéria seca da parte aérea (MSPA) foi proporcionalmente menor ao aumento dos níveis de contaminação (tabela 2). A razão MSR/MSPA foi estatisticamente menor no tratamento de $30 \%$ de contaminação, indicando que o nível de contaminação do solo afetou mais a produção de matéria seca das raízes que da parte aérea. Porém, com tempo de exposição aos metais e, possivelmente, com os danos mais acentuados ao sistema radicular, a produção de fitomassa da parte aérea tornou-se afetada, já que, a redução no sistema radicular resulta em um menor volume de solo explorado o que pode influir, dentre outras características, no balanço nutricional e hídrico da planta.

Sintomas visuais de toxidez foram também verificados para as folhas dos tratamentos com contaminação. Ao final do período experimental, as folhas apresentavam cloroses internervais, necrose, crescimento reduzido e lâmina foliar menos flexível. Redução nos teores de clorofila tem sido relatada por vários autores como respostas de plantas ao estresse por metais pesados (Horváth et al. 1996, Chugh et al. 1999, Di Cagno et al. 1999). Segundo
Stobart et al. (1985), os metais pesados interferem na biossíntese da clorofila através da inibição da formação do ácido $\alpha$-aminolevulínico (ALA), e também da inibição da redutase do protoclorofilídio, a enzima chave da fototransformação do protoclorofilídio-clorofílidio, o que pode resultar em cloroses, afetar a capacidade de assimilação de $\mathrm{CO}_{2}$, e portanto, o crescimento.

O aumento nos níveis de contaminação do solo afetou significativamente a espessura das paredes dos tecidos radiculares (tabela 3 ). Foram observadas paredes mais espessas da epiderme, exoderme e endoderme radicular no tratamento de $30 \%$ de contaminação. O espessamento da epiderme pode ser uma resposta à contaminação aumentando a capacidade de filtro deste tecido, que apresenta maior concentração de cargas negativas, no processo de absorção. A proporção da raiz ocupada pelas barreiras apoplásticas é importante para a proteção de seus tecidos internos contra o efeito tóxico dos íons metálicos. Pela extensão das barreiras apoplásticas e sua composição química, as plantas têm efetivo controle da maior ou menor absorção de água e solutos. A exoderme das raízes das plantas representa uma barreira com resistência variável ao fluxo radial de água e solutos e contribui substancialmente com a resistência em geral (Hose et al. 2001). O aumento na espessura da endoderme pode indicar uma resposta à contaminação, reduzindo, possivelmente, a

Tabela 3. Valores médios de espessura de tecidos radiculares e número de elementos condutores do xilema ( $\mathrm{N}^{\circ}$ vasos do xilema) de plantas jovens de Salix humboldtiana submetidas a diferentes níveis de contaminação do solo por metais pesados. Médias seguidas pela mesma letra na linha, não diferem estatisticamente entre si, pelo teste Tukey a $\mathrm{p} \leq 0,05(\mathrm{n}=5)$.

Table 3. Average values of root tissues thickness and number of conducting elements of xylem ( $\mathrm{N}^{\circ}$ vasos do xilema) of young plants of Salix humboldtiana submitted to different levels of soil contamination from heavy metals. Means followed by the same letter in the row do not differ statistically by the Tukey test at $\mathrm{p} \leq 0.05(\mathrm{n}=5)$.

\begin{tabular}{|c|c|c|c|}
\hline \multirow{3}{*}{$\begin{array}{l}\text { Características } \\
\text { avaliadas }\end{array}$} & \multicolumn{3}{|c|}{ Tratamentos } \\
\hline & Controle & Contaminado & Contaminado \\
\hline & $0 \%$ & $15 \%$ & $30 \%$ \\
\hline Epiderme radicular $(\mu \mathrm{m})$ & $14,2 \mathrm{c}$ & $17,6 b$ & $22,3 a$ \\
\hline Exoderme radicular $(\mu \mathrm{m})$ & $22,8 b$ & $20,1 b$ & $33,7 \mathrm{a}$ \\
\hline Endoderme radicular $(\mu \mathrm{m})$ & ) $10,7 \mathrm{c}$ & $13,4 \mathrm{~b}$ & $24,9 \mathrm{a}$ \\
\hline $\mathrm{N}^{\circ}$ de vasos do xilema & $109,2 \mathrm{~b}$ & $119,6 b$ & $205,2 \mathrm{a}$ \\
\hline
\end{tabular}


translocação de íons metálicos. Muitos estudos relataram que a endoderme é um dos principais locais de alocação de metais pesados nas raízes (Ederli et al. 2004, Lux et al. 2004, Wójcik et al. 2004). Em conjunto, a exoderme e endoderme constituem as principais barreiras apoplásticas das raízes das plantas, e modificações quanto à espessura e constituição química são respostas importantes, em virtude da plasticidade anatômica da espécie, que favorece a tolerância a fatores de estresse.

Os fatores ambientais como seca, salinidade, estresse nutricional e metais pesados são capazes de influenciar a deposição de lignina e suberina nas paredes das células das barreiras apoplásticas (Hose et al. 2001). Zeier \& Schreiber (1998) observou o aumento considerado na quantidade de lignina e suberina depositadas na exoderme de plantas submetidas ao efeito de diferentes fatores externos como o estresse salino $(\mathrm{NaCl})$, osmótico (PEG) e por metais pesados $(\mathrm{Cd})$. O depósito adicional de lamelas de suberina nas células da endoderme não afeta $o$ transporte radial de íons que se movem principalmente pelo transporte simplasto $\left(\mathrm{K}^{+}, \mathrm{PO}_{4}{ }^{3-}\right)$, mas causa inibição do movimento de íons que fluem pelo transporte apoplástico, como ocorre para muitos íons metálicos (Russel \& Clarkson 1975). Lux et al. (2004) trabalhando com clones de Salix contrastantes quanto às características de acumulação e sensibilidade ao $\mathrm{Cd}$, verificou que clones caracterizados por alta tolerância têm elevada proporção de tecido epidérmico, exodérmico e endodérmico, independente de suas características de acumulação e translocação de metais.

Os elementos de transporte do xilema radicular apresentaram paredes mais espessas e maior número no tratamento de maior nível de contaminação (tabela 3). Estudos têm demonstrado que os metais pesados são adsorvidos nas paredes celulares de tecidos radiculares, dentre eles, o xilema (Vásquez et al. 1992, Wójcik et al. 2005). A adsorção dos íons metálicos na parede celular é uma das estratégias da planta, que evita a translocação destes íons para a parte aérea. As fitoquelatinas têm papel importante no seqüestro e compartimentalização de metais pesados (Ederli et al. 2004) e sua produção é rapidamente induzida em células e tecidos expostos aos metais (Rauser 1995). Aumento da lignificação em raízes tem sido verificado em resposta a íons metálicos (Ederli et al. 2004, Lux et al. 2004) o que pode ser associado ao aumento na espessura das paredes celulares devido à possível deposição do metal.

As folhas dos tratamentos contaminados apresentaram largura do feixe vascular da nervura central significativamente superior ao controle, porém, a altura deste feixe não apresentou diferença significante entre os tratamentos (tabela 4). Verificou-se também que a contaminação causou a diminuição no número de elementos condutores do xilema deste feixe (tabela 4). De acordo com Sandalio et al. (2001), os metais pesados podem afetar o movimento de água na planta, reduzir o tamanho e o número de vasos de xilema e ainda alterar o balanço de hormônios, que estão intimamente relacionados à morfogênese dos tecidos. Além disso, um menor número de elementos condutores pode representar menor condutividade hidráulica no xilema e, portanto, menos íons metálicos alcançando a área fotossintética.

A endoderme (bainha do feixe) da nervura central apresentou-se mais espessa no tratamento de maior nível de contaminação (tabela 4). A maior espessura desse tecido pode constituir uma resposta da planta que possivelmente diminui a translocação de metais para o parênquima clorofiliano, evitando assim, possíveis danos ao sistema fotossintético, já que a exposição de plantas aos metais pode afetar o desenvolvimento dos cloroplastos (Stobart et al. 1985). Vollenweider et al. (2006), encontraram uma baixa concentração de $\mathrm{Cd}$ no mesofilo de folhas de Salix viminalis, além de verificar que a distribuição de $\mathrm{Cd}$ entre os tecidos da folha tende a ocorrer de forma a minimizar a quantidade deste metal no parênquima clorofiliano. De fato, o direcionamento do depósito de metais para tecidos não fotossintetizantes pode constituir uma estratégia das plantas na tolerância dos níveis tóxicos de metais pesados.

A espessura do colênquima adaxial não diferiu estatisticamente entre os tratamentos, porém, a espessura do colênquima abaxial aumentou com a elevação da contaminação do solo (tabela 4). O colênquima é um tecido que apresenta células com paredes espessas, cuja dimensão pode alterar em resposta a condições ambientais adversas (Dickison 2000). Na presença de metais pesados, o espessamento do colênquima contribuiria para o aumento na retenção dos íons, e assim reduzir possíveis danos no processo fotossintético. Segundo Wójcik et al. (2005), as paredes celulares são sítios de alocação de metais, e, portanto, maiores extensões de paredes celulares contribuem positivamente com maior retenção destes metais. 
Ainda segundo o autor, as paredes celulares têm demonstrado ser a primeira barreira protegendo o protoplasto da toxidade de metais, e a alocação nas paredes é um mecanismo importante de tolerância, especialmente em baixas concentrações e curtos períodos de exposição aos metais. De acordo com Vollenweider et al. (2006), os tecidos do colênquima consistem num sítio efetivo de retenção de metais

Tabela 4. Valores médios de densidade estomática e espessura de células e tecidos foliares de plantas jovens de Salix humboldtiana submetidas a diferentes níveis de contaminação do solo por metais pesados. Alt. feixe vascular: altura do feixe vascular da nervura central; Larg. feixe vascular: largura do feixe vascular da nervura central; $\mathrm{N}^{\circ}$ xilema feixe vascular: número de elementos condutores do xilema do feixe vascular da nervura central; Dens. Est. Ad.: densidade estomática da epiderme adaxial; DPEEAd: diâmetro polar dos estômatos da epiderme adaxial; DEEEAd: diâmetro equatorial do estômatos da epiderme adaxial; Dens. Est. Ab.: densidade estomática da epiderme abaxial; DPEEAb: diâmetro polar dos estômatos da epiderme abaxial; DEEEAb: diâmetro equatorial do estômatos da epiderme abaxial. Médias seguidas pela mesma letra, na linha, não diferem estatisticamente entre si, pelo teste Tukey a $\mathrm{p} \leq 0,05(\mathrm{n}=5)$.

Table 4. Average values of stomatic density and cell and leaf tissues thickness of young plants of Salix humboldtiana submitted to different levels of soil contamination from heavy metals. Alt. feixe vascular: vascular bundle height; Larg. feixe vascular: vascular bundle width; $\mathrm{N}^{\circ}$ xilema feixe vascular: xylem vessel number of vascular bundle; Dens. Est. Ad.: stomatic density of adaxial epidermis; DPEEAd: polar diameter of stomata of adaxial epidermis; DEEEAd: equatorial diameter of stomata of adaxial epidermis; Dens. Est. Ab.: stomatic density of abaxial epidermis; DPEEAb: polar diameter of stomata of abaxial epidermis; DEEEAb: equatorial diameter of stomata of abaxial epidermis. Means followed by the same letter in the row do not differ statistically by the Tukey test at $\mathrm{p} \leq 0.05(\mathrm{n}=5)$.

\begin{tabular}{lrrr}
\hline \multirow{2}{*}{$\begin{array}{l}\text { Características } \\
\text { avaliadas }\end{array}$} & \multicolumn{3}{c}{ Tratamentos } \\
\cline { 2 - 4 } & $0 \%$ & $15 \%$ & $30 \%$ \\
\hline Controle & Contaminado & Contaminado \\
\hline Alt. feixe vascular $(\mu \mathrm{m})$ & $165,5 \mathrm{a}$ & $165,6 \mathrm{a}$ & $167,3 \mathrm{a}$ \\
Larg. feixe vascular $(\mu \mathrm{m})$ & $162,2 \mathrm{~b}$ & $182,0 \mathrm{a}$ & $197,7 \mathrm{a}$ \\
$\mathrm{N}^{\circ}$ xilema feixe vascular & $54,5 \mathrm{a}$ & $36,1 \mathrm{~b}$ & $37,5 \mathrm{~b}$ \\
Bainha do feixe $(\mu \mathrm{m})$ & $14,1 \mathrm{~b}$ & $16,5 \mathrm{ab}$ & $17,5 \mathrm{a}$ \\
Colênquima adaxial $(\mu \mathrm{m})$ & $43,1 \mathrm{a}$ & $39,4 \mathrm{a}$ & $53,7 \mathrm{a}$ \\
Colênquima abaxial $(\mu \mathrm{m})$ & $47,1 \mathrm{c}$ & $55,9 \mathrm{~b}$ & $71,1 \mathrm{a}$ \\
Epiderme adaxial $(\mu \mathrm{m})$ & $14,0 \mathrm{a}$ & $11,2 \mathrm{~b}$ & $11,8 \mathrm{~b}$ \\
Epiderme abaxial $(\mu \mathrm{m})$ & $12,2 \mathrm{a}$ & $11,7 \mathrm{a}$ & $10,1 \mathrm{a}$ \\
Mesofilo $(\mu \mathrm{m})$ & $181,7 \mathrm{a}$ & $182,1 \mathrm{a}$ & $165,8 \mathrm{~b}$ \\
Dens. Est. Ad. $\left(\mathrm{n}^{\circ} / \mathrm{mm}^{2}\right)$ & $165,6 \mathrm{~b}$ & $303,5 \mathrm{a}$ & $275,9 \mathrm{a}$ \\
Dens. Est. Ab $\left(\mathrm{n}^{\circ} / \mathrm{mm}^{2}\right)$ & $181,2 \mathrm{~b}$ & $258,1 \mathrm{a}$ & $284,2 \mathrm{a}$ \\
DPEEAd $(\mu \mathrm{m})$ & $27,9 \mathrm{a}$ & $23,6 \mathrm{c}$ & $26,1 \mathrm{~b}$ \\
DEEEAd $(\mu \mathrm{m})$ & $18,9 \mathrm{a}$ & $15,0 \mathrm{c}$ & $16,8 \mathrm{~b}$ \\
DPEEAb $(\mu \mathrm{m})$ & $24,7 \mathrm{a}$ & $24,2 \mathrm{a}$ & $24,1 \mathrm{a}$ \\
DEEEAb $(\mu \mathrm{m})$ & $14,2 \mathrm{a}$ & $16,0 \mathrm{a}$ & $15,3 \mathrm{a}$ \\
\hline
\end{tabular}

no apoplasto, pois, as maiores concentrações de $\mathrm{Cd}$ foram verificadas nesse tecido em comparação com os demais tecidos foliares.

As plantas dos tratamentos com contaminação apresentaram epiderme da face adaxial das folhas com menor espessura em relação ao controle (tabela 4). Não foi verificada diferença quanto à espessura da epiderme da face abaxial entre os tratamentos (tabela 4). De acordo com Vollenweider et al. (2006) o efeito do Cd nas plantas causa colapso de células da epiderme da face adaxial das folhas, deposição de compostos polifenílicos e maior espessamento das paredes celulares das células epidérmicas de ambas as faces do limbo foliar. Além disso, por interferir no processo de expansão e no teor relativo de água das células (Barceló et al. 1990) os metais pesados são capazes de causar a redução na extensibilidade celular, o que justificaria menor espessura do tecido epidérmico em folhas de plantas expostas à contaminação por metais pesados.

O mesofilo foliar apresentou menor espessura no tratamento 30\% (tabela 4). Segundo Melo et al. (2007), algumas espécies desenvolvem mudanças na espessura de tecidos do mesofilo foliar que possibilitam uma melhor plasticidade a diferentes condições de estresse. Estudos têm demonstrado que a exposição das plantas aos metais pesados causa a diminuição no tamanho das células do mesofilo (Srighar et al. 2005, Zhao et al. 2000), bem como o colapso de células dos parênquimas paliçádico e lacunoso (Sirdhar et al. 2005). A diminuição dos espaços intercelulares das folhas, que dificulta o deslocamento de compostos fitotóxicos nos tecidos vegetais, tem sido verificada em plantas expostas à poluição (Alves et al. 2001). Em conjunto, somados à menor espessura da epiderme adaxial, esses fatores podem justificar a menor espessura do limbo foliar das plantas do tratamento de maior nível de contaminação.

$\mathrm{O}$ número de estômatos por $\mathrm{mm}^{2}$ de ambas as faces da epiderme foliar foi maior nos tratamentos com solo contaminado (tabela 4). O diâmetro polar (DP) e equatorial (DE) dos estômatos da face abaxial não diferiu estatisticamente entre os tratamentos, já a face adaxial, apresentou DP e DE maiores no controle, seguidos pelo tratamento de $30 \%$ e $15 \%$ (tabela 4). Aumento na densidade estomática de folhas em condições de estresse por $\mathrm{Cd}$ tem sido verificado em Silene vulgaris (Chardonnens et al. 1998) e em Brassica napus (Baryla et al. 2001). Abrams et al. (1994) correlacionaram o comprimento da célula 
estomática positivamente à condutância estomática.

As variações anatômicas encontradas em S. humboldtiana correspondem à aquelas encontradas em outros estudos (Ederli et al. 2004, Lux et al. 2004, Wójcik et al. 2004, Vollenweider et al. 2006), ressaltando a importância das características anatômicas e fisiológicas no aumento da tolerância das espécies aos metais pesados. A habilidade da espécie em ajustar a sua anatomia às condições do meio, sugerem sua plasticidade fenotípica.

\section{Agradecimentos}

Os autores agradecem à Fundação de Amparo à Pesquisa do Estado de Minas Gerais (FAPEMIG) pelo financiamento da pesquisa e pela concessão de bolsa de iniciação científica (PIBIC/FAPEMIG) ao primeiro autor.

\section{Literatura citada}

Abrams, M.D., Kubiske, M.E. \& Mostoller, S.A. 1994. Relating wet and dry year ecophysiology to leaf structure in contrasting temperature tree species. Ecology 75: 123-133.

Alves, E.S., Giusti, P.M. \& Domingos, M. 2001. Estudo anatômico foliar do clone híbrido 4430 de Trandescantia hibrid: alterações decorrentes da poluição aérea. Revista Brasileira de Botânica 24: 561-566.

Barceló, J., Vásquez, M.D. \& Poshenrieder, C.H. 1990. Plant water relations as affected by heavy metal stress: A review. Journal of Plant Nutrition 13: 1-37.

Baryla, A., Carrier, P., Franck, F., Coulomb, C., Sahut, C. \& Havaux, M. 2001. Leaf cloroses in oilseed rape plants (Brassica napus) grown o cadmium-polluted soil: causes and consequences for photosynthesis and growth. Planta 212: 696-709.

Benavides, M.P., Gallego, S.M. \& Tomaro, M.L. 2005. Cadmium toxicity in plants. Brazilian Journal of Plant Physiology 17: 21-34.

Cagno, R., Guidi, L., Stefani,A. \& Soldatini, G.F. 1999. Effects of cadmium on growth of Helianthus annus seedlings: physiological aspects. New phytologist 144: 65-71.

Castro, E.M., Pinto, J.E.B.P., Soares, A.M., Melo, H.C., Bertalucii, S.K.V., Vieira, C.V. \& Junior, E.C.L. 2007. Adaptações anatômicas de folhas de Mikania glomerata Sprengel (Asteraceae), em três regiões distintas da planta, em diferentes níveis de sombreamento. Revista Brasileira de Plantas Medicinais 9: 8-16.

Chardonnens, A.N., Ten Bookum, W.M., Kuijper, D.J., Verkleij, J.A.C. \& Ernest, W.H.O. 1998. Distribution of cadmium in leaves of cadmium tolerant and sensitive ecotypes of Silene vulgaris. Physiologia Plantarum 104:
75-80.

Chugh, L.K. \& Sawhney, S.K. 1999. Photosynthetic activities of Pisum sativum seedlings grown in presence of cadmium. Plant Physiology and Biochemistry 37: 297-303.

Degenhardt, B. \& Gimmler, H. 2000. Cell wall adaptations to multiple environmental stresses in maize roots. Journal of Experimental Botany 51: 595-603.

Dickson, W.C. 2000. Integrative plant anatomy. Academic Press, San Diego.

Ederli, L., Reale, L., Ferranti, F. \& Pasqualini, S. 2004. Responses induced by high concentration of cadmium in Phragmites australis roots. Physiologia Plantarum 121: 66-74.

Enstone, D.E., Peterson, C.A. \& Ma, F. 2003. Root endodermis and exodermis: Structure, function, and responses to the environment. Journal of Plant Growth Regulation 21: 335-351.

Ferreira, D.F. 1999. Sisvar 4. 3-Sistema de analises estatísticas. Universidade Federal de Lavras, Lavras.

Forster, J.C. 1995. Heavy metals. In: K. Alef. \& P. Nannipieri (eds.). Methods in applied soil microbiology and biochemistry. Academic Press, London, pp. 1001-1043.

Greger, M. \& Landeberg, T. 1999. Use of willow in phytoextraction. International Journal of Phytoremediation 1: 115-123.

Hose, E., Clarkson, D.T., Steudle, L. \& Hartung, W. 2001. The exodermis: a variable apoplástica barrier. Journal of Experimental Botany 52: 2245-2264.

Horváth, G., Droppa, M., Orazeez,A., Raskin, V.I. \& Arder, J.B. 1996. Formation of the photosynthetic apparatus during greening of cadmium-poisoned barley leaves. Planta 199: 238-243.

Johansen, D.A. 1940. Plant microtechinique. 2 ed. Mc GrawHill, New York.

Kabata-Pendias, A. \& Pendias, H. 1992. Trace elements in soils an plants. 2 ed. CRC Press, Boca Raton.

Kraus, J.E. \& Arduin, M. 1997. Manual básico de métodos em morfologia vegetal. Editora da Universidade Federal Rural do Rio de Janeiro, Seropédica.

Lorenzi, H. 1992. Árvores brasileiras: manual de identificação e cultivo de plantas arbóreas nativas do Brasil. v.3. Plantarum, Nova Odessa.

Lux, A., Sottniková, A., Opatrná, J. \& Greger, M. 2004.Differences in struture of adventitions roots in Salix clones with contrasting characteristics of cadmium accumulation and sensitivity. Physiologia Plantarum 120:537-545.

Marques, T.C.L.L.S.M., Moreira, F.M.S. \& Siqueira, J.O. 2000.Crescimento e teor de metais de mudas de espécies arbóreas cultivadas em solo contaminado com metais pesados. Pesquisa Agropecuária Brasileira 35: 121-132.

Meagher, R.B. \& Heaton, A.C.P. 2005. Strategies for the engineered phytoremediation toxic element pollution: mercury and arsenic. Journal of Industrial Microbiology 
and Biotechnology 32: 502-513.

Melo, H.C., Castro, E.M., Soares, A.M., Melo, L.A. \& Alves, J.D. 2007. Alterações anatômicas e fisiológicas em Setaria anceps Stapf ex Massey e Paspalum paniculatum L. sob condições de déficit hídrico. Hoehnea 34: 145-153.

North, G.R. \& Nobel, P.S. 1995. Hydraulic conductivity of concentric root tissues of Agave deserti Engelm. Under wet and drying conditions. New Phytologist 130: 47-57.

Perumalla, C.J. \& Peterson, C.A. 1986. Deposition of Caspary bands and suberin lamellae in the exodermis and endodermis of young corn and onion roots. Canadian Journal of Botany 64: 1873-1878.

Rauser W.E. 1995. Phytochelatins and related peptides. Structure, biosynthesis and function. Plant Physiology 109: 1141-1149.

Reinhardt, D.H. \& Rost, T.L. 1995.Salinity accelerates endodermal development and induces an exodermis in cotton seedling roots. Environmental and Experimental Botany 35: 563-674.

Russel, R. S. \& Clarkson, D.T. 1975. Ion transport in root systems. In: N. Sunderland (ed.). Perspectives in Experimental Biology, v.10. Pergamon Press, Oxford, pp. 401-411.

Sanità-di-Toppi, L. \& Gabbrielli, R. 1999. Response to cadmium in higher plants. Environmental and Experimental Botany 41: 105-130.

Sandalio, L.M., Dalurzo, H.C., Gómez, M., Romero-Puertas, M.C. \& Del Rio, L.A. 2001. Cadmium-induced changes in the growth and oxidative metabolism of pea plants.
Journal of Experimental Botany 52: 2115-2126.

Srighar, B.B.M., Diehl, S.V., Hanc, F.X., Monts, D.L. \& Sub, Y. 2005. Anatomical changes due to uptake and accumulation of $\mathrm{Zn}$ and $\mathrm{Cd}$ in indian mustard (Brassica juncea). Environmental and Experimental Botany 54: 131-141.

Stobart, A.R., Griffiths, W.T., Ameen-Bi-Khari, J. \& Shewood, R.P. 1985. The effect of $\mathrm{Cd}^{2+}$ on the biosynthesis of chlorophyll in leaves of barley. Physiologia Plantarum 63: 293-298.

Vásquez, M.D., Poschenrieder, C.H. \& Barceló, J. 1992. Ultrastructural effects and localization of low cadmium concentrations in bean roots. New Phytologist 140: 350-355.

Vollenweider, P., Cosio, C., Günthardt-Goerg, M. \& Keller, C. 2006. Localization and effects of cadmium in leaves of a cadmium-tolerant willow (Salix viminalis L.) Part II Microlocalization and cellular effects of cadmium. Environmental and Experimental Botany 58: 25-40.

Wójcik, M., Vangronsveld, J., D’Haen, J. \& Tukiendorf, A. 2005. Cadmium tolerance in Thlaspi caerulescens. Environmental and Experimental Botany 53: 163-171.

Zeier, J. \& Schreiber, L. 1998. Comparative investigation of primary and tertiary endodermal cell walls isolated from the roots of monocotyledonous species: chemical composition in relation to fine structure. Planta 206: 349-361.

Zhao, F.J., Lombi, E., Breedon, T. \& Mcgrath, S.P. 2000. Zinc hyperaccumulation and cellular distribution in Arabidopsis halleri. Plant Cell Environment 23: 507-514. 